\title{
LETTER
}

\section{Response to 'Adipokines, inflammation, insulin resistance, and carotid atherosclerosis in patients with rheumatoid arthritis'}

\author{
Miguel A Gonzalez-Gay ${ }^{1 *}$, Raquel Lopez-Mejias', Carlos Gonzalez-Juanatey ${ }^{2}$ and Javier Llorca ${ }^{3,4}$ \\ See related research by Kang et al., http://arthritis-research.com/content/15/6/R194
}

In a recent report in Arthritis Research \& Therapy, Kang and colleagues [1] assessed a series of patients with rheumatoid arthritis (RA) to establish whether adipokines could be a link between inflammation, insulin resistance, and atherosclerosis in RA.

We have noticed that Kang and colleagues did not pay attention to our former studies on the same issue. In this regard, in the last decade, we conducted a series of studies on insulin resistance and adipokines in a cohort of Spanish patients with long-standing RA, undergoing anti-tumor necrosis factor-alpha (anti-TNF- $\alpha$ ) infliximab therapy because of severe disease, refractory to conventional disease-modifying anti-rheumatic drugs [2-6].

Kang and colleagues described that resistin was associated with erythrocyte sedimentation rate (ESR) $(r=0.322$, $P<0.001)$, C-reactive protein (CRP) $(r=0.209, P=0.004)$, and increased disease duration $(r=0.176, P=0.014)$ [1]. These data are not new. We previously reported a close association between laboratory markers of inflammation, particularly CRP and resistin levels [3]. In our series, we found a significant association between the mean ESR $(r=0.405, P=0.03)$ and CRP $(r=0.571, P=0.0005)$ from disease diagnosis and ESR $(r=0.486, P=0.004)$, CRP $(r=$ $0.599, P=0.0005)$, and platelet count $(r=0.559, P=$ 0.0007) at the time of the study and resistin levels [3]. These findings, along with these new data described by Kang and colleagues, highlight the potential role of resistin in the inflammatory cascade in RA.

Kang and colleagues also found a positive correlation between adiponectin and ESR $(r=0.162, P=0.025)$ [1]. Prior to these results, in our series of patients with

\footnotetext{
* Correspondence: miguelaggay@hotmail.com

${ }^{1}$ Epidemiology, Genetics and Atherosclerosis Research Group on Systemic Inflammatory Diseases, Rheumatology Division, Hospital Universitario Marqués de Valdecilla, IFIMAV, Avenida de Valdecilla s/n, 29008 Santander, Spain

Full list of author information is available at the end of the article
}

severe and active disease despite anti-TNF- $\alpha$ therapy, we observed that high-grade inflammation was independently and negatively correlated with circulating adiponectin concentrations [4]. CRP levels correlated with circulating adiponectin concentrations (partial $\mathrm{r}(\mathrm{pr})=$ $-0.370, P=0.04$ ), independently of age and gender [4]. In contrast, low adiponectin levels clustered with metabolic syndrome features that contribute to atherogenesis in RA [4]. Adiponectin concentrations correlated with triglycerides/high-density lipoprotein (HDL) cholesterol ratios $(\mathrm{pr}=-0.396, P=0.03)$, total cholesterol/HDL cholesterol ratios $(\mathrm{pr}=-0.444, P=0.01)$, and high fasting plasma glucose levels $(\mathrm{pr}=-0.366, P=0.04$ ), independently of CRP levels and the body mass index [4]. These results also suggest an implication of adiponectin in the development of cardiovascular disease in RA.

In the series by Kang and colleagues, leptin was associated with homeostasis model assessment-estimated insulin resistance $(r=0.369, P<0.001)$ [1]. In our series of RA patients with active disease despite anti-TNF- $\alpha$ therapy, there was a positive correlation between body mass index of RA patients and serum leptin levels $(r=0.665$, $P<0.001)$ [5]. Also, a significant correlation of leptin with biomarkers of endothelial activation (vascular cell adhesion molecule- $1 ; r=0.349, P=0.04$ ) was observed [5]. However, no significant correlations between leptin levels and disease duration, ESR and CRP levels, disease activity score using 28 joint counts, lipids, insulin sensitivity, resistin, adiponectin, or the cumulative prednisone dose at the time of the study were found [5]. Therefore, in Western patients with severe and active RA, leptin levels seem to be related to adiposity [5]. However, in our series, circulating visfatin levels were unrelated to disease activity, adiposity, or metabolic syndrome [6].

Although adipokines have been demonstrated to exert a key role in the interface between obesity, inflammation, insulin resistance, and atherosclerosis in the general 
population, we agree with Kang and colleagues that information on their potential contribution is still limited in RA. In this regard, in Western individuals with RA, adipokines have not been demonstrated to represent a significant risk factor for indirect measures of organic arterial wall atherosclerotic damage, as assessed by carotid intima-media thickness in our cohort of longstanding active RA patients undergoing infliximab treatment [7], or by coronary artery calcification evaluation, as shown in recent work by Rho and colleagues [8].

\section{Abbreviations}

anti-TNF-a: Anti-tumor necrosis factor-alpha; CRP: C-reactive protein; ESR: Erythrocyte sedimentation rate; HDL: High-density lipoprotein; $\mathrm{RA}$ : Rheumatoid arthritis.

\section{Competing interests}

The authors declare that they have no competing interests.

\section{Authors' contributions}

MAG-G made substantial contributions to conception and design of the manuscript, helped to draft the manuscript, and has given final approval of the version to be published. RL-M, CG-J, and $J \mathrm{~L}$ helped in the design of the manuscript and drafted the manuscript. All authors have read and approved the final manuscript.

\section{Acknowledgments}

The studies on rheumatoid arthritis by the MAG-G group were supported by 'Fondo de Investigaciones Sanitarias' grants PI06/0024, PS09/00748, and PI12/ 00060 (Spain). This work was also partially supported by RETICS Programs RD08/0075 (RIER) and RD12/0009/0013 from the 'Instituto de Salud Carlos III' (ISCIII) (Spain). RL-M is a recipient of a Sara Borrell postdoctoral fellowship from the Instituto Carlos III de Salud at the Spanish Ministry of Health (Spain).

\section{Author details}

${ }^{1}$ Epidemiology, Genetics and Atherosclerosis Research Group on Systemic Inflammatory Diseases, Rheumatology Division, Hospital Universitario Marqués de Valdecilla, IFIMAV, Avenida de Valdecilla s/n, 29008 Santander, Spain. ${ }^{2}$ Division of Cardiology, Hospital Universitario Lucus Augusti, Calle San Cibrao s/n, 27003 Lugo, Spain. ${ }^{3}$ Division of Epidemiology and Computational Biology, School of Medicine, University of Cantabria, Santander, Spain. ${ }^{4}$ CIBER Epidemiología y Salud Pública (CIBERESP), IFIMAV, Avenida Cardenal Herrera Oria s/n, 29011 Santander, Spain.

Published: 10 Feb 2014

\section{References}

1. Kang Y, Park HJ, Kang MI, Lee HS, Lee SW, Lee SK, Park YB: Adipokines, inflammation, insulin resistance, and carotid atherosclerosis in patients with rheumatoid arthritis. Arthritis Res Ther 2013, 15:R194.

2. Gonzalez-Gay MA, De Matias JM, Gonzalez-Juanatey C, Garcia-Porrua C Sanchez-Andrade A, Martin J, Llorca J: Anti-tumor necrosis factor-alpha blockade improves insulin resistance in patients with rheumatoid arthritis. Clin Exp Rheumatol 2006, 24:83-86.

3. Gonzalez-Gay MA, Garcia-Unzueta MT, Gonzalez-Juanatey C, Miranda-Filloy JA, Vazquez-Rodriguez TR, De Matias JM, Martin J, Dessein PH, Llorca J: Anti-TNF-alpha therapy modulates resistin in patients with rheumatoid arthritis. Clin Exp Rheumatol 2008, 26:311-316.

4. Gonzalez-Gay MA, Llorca J, Garcia-Unzueta MT, Gonzalez-Juanatey C, De Matias JM, Martin J, Redelinghuys M, Woodiwiss AJ, Norton GR, Dessein PH: High-grade inflammation, circulating adiponectin concentrations and cardiovascular risk factors in severe rheumatoid arthritis. Clin Exp Rheumatol 2008, 26:596-603.

5. Gonzalez-Gay MA, Garcia-Unzueta MT, Berja A, Gonzalez-Juanatey C, Miranda-Filloy JA, Vazquez-Rodriguez TR, de Matias JM, Martin J, Dessein PH, Llorca J: Anti-TNF-alpha therapy does not modulate leptin in patients with severe rheumatoid arthritis. Clin Exp Rheumatol 2009, 27:222-228.
6. Gonzalez-Gay MA, Vazquez-Rodriguez TR, Garcia-Unzueta MT, Berja A, Miranda-Filloy JA, de Matias JM, Gonzalez-Juanatey C, Llorca J: Visfatin is not associated with inflammation or metabolic syndrome in patients with severe rheumatoid arthritis undergoing anti-TNF-alpha therapy. Clin Exp Rheumatol 2010, 28:56-62.

7. Gonzalez-Gay MA, Gonzalez-Juanatey C, Rodriguez-Rodriguez L, Miranda-Filloy JA, Martin J, Llorca J: Lack of association between adipokines and ghrelin and carotid intima-media thickness in patients with severe rheumatoid arthritis. Clin Exp Rheumatol 2011, 29:358-359.

8. Rho YH, Chung CP, Solus JF, Raggi P, Oeser A, Gebretsadik T, Shintani A Stein CM: Adipocytokines, insulin resistance, and coronary atherosclerosis in rheumatoid arthritis. Arthritis Rheum 2010, 62:1259-1264.

10.1186/ar4478

Cite this article as: Gonzalez-Gay et al:: Response to 'Adipokines, inflammation, insulin resistance, and carotid atherosclerosis in patients with rheumatoid arthritis'. Arthritis Research \& Therapy 2014, 16:401 